\title{
Digital Economy and Legal Issues
}

\author{
Larisa V. Sannikova ${ }^{1, *}$, Yuliya S. Kharitonova ${ }^{2}$ \\ ${ }^{1}$ The Institute of State and Law of the Russian Academy of Sciences, Moscow, Russia \\ ${ }^{2}$ Lomonosov Moscow State University, Moscow, Russia \\ *Corresponding author
}

Keywords: Digital Economy, Digital Technologies, Blockchain.

\begin{abstract}
Article is devoted to the problems of legal regulation of the digital economy. Based on the analysis of various approaches to the definition of the digital economy, the article concludes that, as the core of the digital economy and its essence, it is advisable to consider only those economic relations whose object is digital assets created and managed by digital technologies. The authors highlight the difference between digital objects and objects in electronic form. The danger of confusing the concepts of "electronic" and "digital" is that the application of digital technologies for the problems of the state and business provides much more efficiency than the simple application of electronic form instead of paper. It is noted that for the development of the digital economy it is necessary to create appropriate legal regulation that would provide legal clarity and protection of violated rights for all its participants. The article explores experience of different countries (USA, Malta, Russia), which regulate the use of digital technologies.
\end{abstract}

\section{Introduction}

The national program "Digital economy", adopted in Russia in February of 2019, aroused interest to the concept of "Digital economy", both among practitioners and among scientists. Such interest is quite reasonable, since without understanding of this concept it is very complicated to analyze formation and development of the digital economy in Russia, as well as the measures for the implementation of this program.

It is admitted, that the term "digital economy" was implemented into scientific community by Don Tapscott [1]. Although, he did not define the digital economy, he drawn up the basic features of the new economy. Digitalization require special attention among other features, it is understood as a digital form of information that allows using digital devices to freely transfer a huge amount of information in the shortest possible time between people in different parts of the world.

It should be noted, that internet technologies are considered as the main part of Tapscott's conception of digital economy. As it is marked in the literature, the concept of the digital economy has been transformed with the development of IT-technologies by specifying mobile and wired networks, cloud technologies, big data technologies, etc, as its drivers and other technologies [2]. In this regard, most documents, both at the Russian and international level, apply the facilitated concept of the digital economy as an economy based on digital technologies. This broad concept allows to cover the whole range of phenomena associated with the use of digital technologies. 


\section{Challenges in Defining the Digital Economy}

New technologies in the economy revealed in the formation of open labor market and peer-topeer production, based on the mass-collaboration and collective intelligence, in the opening of new opportunities for co-sharing ownership, public ownership of intellectual property (Creative Commons licenses, CC) and General Public License (GPL)» [3]. Under their influence, the economy began to acquire special features that seem to contradict the classical economic doctrine and the doctrine of companies' effective management in market conditions: the on-Demand Economy, the Sharing Economy, the Cooperation economy, the Wikinomics [4], the Hi-Tech Gift Economy.

Russian researchers consider digital economy as a technological part of economy [5]. However, foreign scientists note that "while more service providers, manufacturers of finished products and even suppliers of raw materials involve ICT in their activities, the digital economy in current conditions transforms into the simple "economy" [2]. The digital economy in this sense does not abolish the real economy, and is often inextricably connected with the production of goods, services and work in the real world. Digitalization of the economy allows to solve the problems of reducing transaction costs and the corresponding reduction of the market entrance limit, expanding the opportunities of small businesses and accelerating transactions.

It should be recognized that the digital economy is a multilateral, multidimensional phenomenon, which makes it difficult to form a single concept. A broad approach to the concept of the digital economy as to an economy based on digital technologies is highly demanded to describe the wide economic transformations occurring under the influence of digital technologies.

However, for the research of individual processes and phenomena arising in the economy as a result of the use of new digital technologies, it is necessary to limit the concept of the digital economy.

Foreign economists R. Buch and R. Hicks propose as an option for limiting digital economy concept to use the criterion of extensive and intensive application of information and computer technologies (ICT). As R. Higgs points out, "the easiest way to determine whether a given activity is a product of extensive ICT use is to ask whether this activity is possible only through ICT". If the answer is negative and the questioned phenomenon existed before the introduction of ICT, then we are dealing with intensive application of ICT. If the answer is positive and the activity in question is only possible through ICT, then it means that ICT is applied extensively» [2].

It seems that the category of activity is too broad and uncertain to be applied in this background. Such type of activity as payment existed before the appearance of cryptocurrencies, but cryptocurrencies is the kind of phenomenon, which existence is impossible without the use of appropriate digital technologies.

In this regard, in our opinion, it is advisable to consider as the core of the digital economy and as its essence only those economic relations, which object is digital assets created and operated due to digital technologies.

As the example of bitcoin demonstrates, a new technology becomes valuable when a new economic benefit such as a product or service is created on its basis. It was with the creation and spread of bitcoin when the blockchain technology was recognized, but the idea of it was described by Stuart Haber and W. Scott Stornett even in 1991. The new economic benefits created by the application of digital technologies have been commonly referred to as "digital assets". Digital assets are considered by modern economists as an essential element of the digital economy [6]. 


\section{Digital vs. Electronic}

In the proposed approach to understanding of the digital economy concept, the processes of digitalization associated with the creation and circulation of new economic benefits, commonly referred to as digital assets, are distinguished from related processes where digital technologies can be used to some extent. The processes of digitalization and transition to electronic document management can be named as an examples. They are, of course, required for the functioning of the digital economy, but they are characterised as secondary, auxiliary.

The digitalization is the transition of an object from analog to digital form. The digitalization is required for recording an object on a digital device and its moving within digital space. Objects of digitization can be printed texts (books, documents), audio and video recordings, images, etc.

The digitalization of documents is one of the components of the electronic document management system. Electronic document management is in demand both in public administration and in business, as its implementation reduces the time and material costs for drafting, processing and transfer of documents.

In business electronic document management allows to optimize business processes, and, consequently, to increase the profit of the company. In the sphere of public administration, interagency electronic document management is in demand, which increases the efficiency of interagency cooperation. What is more, electronic document management contributes to a more complete and rapid satisfaction of citizens' needs in the provision of public services.

Under the Russian State Standard (GOST R) No 52292-2004 "Information technology (IT). Electronic exchange of information. Terms and definitions" point 4.2.12 an electronic document is defined as "a form of representation of a document as a set of interrelated implementations in an electronic sphere and their corresponding interrelated implementations in a digital environment." The electronic sphere refers to the sphere of technical devices which carry out the implementation of an electronic document, for example, storage as a file on a disk and its reproduction on a monitor screen. A digital sphere is a sphere of logical objects in which information is represented as a bit string which means a set of zeros and ones. In the electronic sphere, this information is interpreted by the appropriate method and thus becomes available for perception.

Therefore, from a technical point of view, an electronic document has a digital essence, which can be implemented only in an electronic sphere. That is, an electronic document means an inseparable unity of electronic form and digital content.

In this regard, there is a question whether the electronic document and electronic document management can be attributed to the phenomena that are elements of the digital economy and digitalization in a broad sense. As it was proved already, if we consider an electronic document only from a technical point of view, then its attribution to the so-called digital objects would be reasonable.

However, this approach is a substitution of concepts. Digitalization involves the use of advanced digital technologies. It is the introduction of digital technologies that should ensure the technological breakthrough of the country. And the transition to the electronic format in interaction does not require fundamentally new technological methods based on digital technologies. Therefore, there is no need to find new legal models to regulate these relations.

Many legal phenomena exist in electronic (digital) form for a long time and their legal regulation did not cause special difficulties. Examples are the legislative regulation of electronic document management, electronic digital signature, etc.

It should be noted that the digital economy is often considered as a relation of subjects that transmit documents via the Internet, i.e. the relationship of electronic document management. Thus, some authors, talking about how the Russian authorities demonstrate the desire to transit to the digital economy, note the transfer to electronic form and acceleration of data processing, which are 
prepared and sent as reports to government agencies [7]. These changes in the interaction between the state and business are called "digitalization" by mistake.

It seems that the danger of confusing the concepts of "electronic" and "digital" is that the application of digital technologies for the problems of the state and business provides much more efficiency than the simple application of electronic form instead of paper.

\section{Formation of the Legal and Regulatory Framework for the Digital Economy}

The development of the digital economy is impossible without the creation of appropriate legal regulation that would provide legal clarity and protection of violated rights for all its participants.

Tasks of creating a system of legal regulation of the digital economy are as follows: creation of legal conditions for the formation of electronic civil management; providing enabling legal environment for data collection, storage and processing; providing legal conditions for the introduction and use of innovative technologies in financial markets; adoption of regulatory legal acts to stimulate the development of the digital economy (mainly in the field of taxation, authors note); ensuring regulation of digital interaction between the business community and the state and other.

The solution of these tasks involves the adoption of some Federal laws and amendments to the existing Federal laws. The analysis of the Federal project "Normative regulation of the digital sphere" proves that the majority of normative legal acts provided in it are directed mainly to legal regulation of relations on the organization of electronic interaction and electronic management. It is unlikely that with this approach the implementation of The national program "Digital economy" will provide the "leap into the future", which is expected by the country's authority .

Without denying the expediency and necessity of adoption of legal acts which are provided by the considered Federal project, we believe that they are insufficient for creation of favorable legal environment for introduction and use of digital technologies.

In fact, only one area of regulation outlined in the Federal project is aimed at the problems of introduction and use of innovative technologies, and it concerns only financial markets.

It must be admitted that innovative technologies in the financial sector led to the discovery of digital assets, such as bitcoin, and became the drivers for the digital economy. However, the scope of application of new digital technologies is not limited to financial markets, as the experience of foreign countries shows.

In this regard, the experience of the countries that regulate the application of digital technologies is of interest.

Thus, the obvious advantages of blockchain technologies for maintaining the register of shareholders induced the legislators of the state of Delaware to amend the corporate legislation of the state, allowing the use of distributed registry technologies, in particular blockchain, for maintaining the register of shareholders and making any records on the transmiting of securities, including the issue and transfer of shares [8].

Malta's legislators have approached the problem more globally, creating a comprehensive regulatory framework for the use of distributed registry technologies: The Malta Digital Innovation Authority Act (MDIA); The Innovative Technology Arrangement and Services Act (ITAS); The Virtual Financial Assets Act (VFAA). The peculiarity of the Maltese approach is well reflected in the phrase "technology first". Unlike other leading countries, which are trying to cover the new sphere of digital assets with single changes in financial regulation laws, Maltese legislators have chosen to form a fundamentally new infrastructure, where financial digital assets are considered only as a part. It should be noted that this approach differs from the position of Russian lawyers, who share mostly the principle of "technological neutrality of legislation". 


\section{Conclusion}

The time will show which regulatory model is optimal for the development of the digital economy. Since the appearance of bitcoin and the development of crypto markets, various countries at certain stages have become leaders in regulation of circulation of crypto assets (for example, first China, then Switzerland, at the moment it is Malta), however, no one has managed to keep this leadership and show sustainable development.

In any case, the formation of the regulatory framework should be based on a full understanding of the technical nature of the digital technologies used; taking into account the economic characteristics of the new economic benefits arising from the use of digital technologies (digital assets); compliance with legal traditions, the which application should be suited to regulate new social relations.

\section{Acknowledgement}

This research was supported by the Russian Foundation for Basic Research via grant No: 18-2916145 MK “The Mechanism of legal regulation of relations using the Distributed Ledger Technology”.

\section{References}

[1] Tapscott D. The digital economy: Promise and peril in the age of networked intelligence. - New York : McGraw-Hill, 1996.

[2] Bukht R., Hicks R. Definition, concept and measurement of the digital economy // Bulletin of international organizations. 2018. Vol. 13. No. 2.

[3] Markova V. D. Digital economy. Textbook. Moscow: Infra-M, 2018

[4] Tapscott D., William E. Wikinomics. How mass collaboration changes everything. URL: http://www.litmir.co/bd/?b=137942.

[5] Ivanov V. V., Malinetsky G. G. Digital economy: myths, reality, perspective. M.: Russian Academy of Sciences. 2017.

[6] Bolt U. How a Digital-Assets Ecosystem Could Jumpstart an Inclusive Digital Economy. 11.07.2019. URL: https://internationalbanker.com/technology/how-a-digital-assets-ecosystemcould-jumpstart-an-inclusive-digital-economy/

[7] Digital economy. When will companies be exempt from reporting? // Raschet. 2018. No. 3.

[8] Strassman R. Delaware Explicitly Legalizes Corporate Documentation via Blockchain. URL: https://www.bu.edu/rbfl/files/2018/03/166-176.pdf 